\title{
Argamassa com areia proveniente da britagem de resíduo de construção civil - Avaliação de características físicas e mecânicas
}

\author{
Mortar with sand from crushing of construction \\ waste - Assessment of physical and \\ mechanical characteristics
}

Lia Lorena Pimentel ${ }^{1}$,Osvaldo Pissolato Junior ${ }^{2}$, Ana Elisabete Paganelli Guimarães de A. Jacintho ${ }^{1}$,

Heline Laura de Sousa Martins ${ }^{3}$

\author{
${ }^{1}$ ProfaDra do Programa de Pos Graduação em Sistemas de Infraestrutura Urbana-PUC-Campinas , Campinas, SP \\ e-mail: lialp@puc-campinas.edu.br, anajacintho@gmail.com \\ ${ }^{2}$ Prof. Ms Faculdade de Arquitetura e Urbanismo-PUC-Campinas \\ e-mail: osv.pizzolato@gmail.com \\ ${ }^{3}$ Graduanda Faculdade de Engenharia Ambiental e Sanitária-PUC-Campinas \\ e-mail: heline_laura@hotmail.com
}

\section{RESUMO}

A preocupação com o meio ambiente, devido a grande quantidade de resíduos da construção civil que são descartados de forma inadequada, incentivou o processamento destes com o intuito de retorná-los ao sistema produtivo. Os estudos com o objetivo de intensificar o reaproveitamento dos resíduos da construção civil se intensificaram recentemente, desenvolvendo normas para produção, avaliação e utilização dos agregados reciclados, para os quais o consumo ainda é incipiente. Para o desenvolvimento do trabalho foram determinadas as características dos agregados reciclados e natural, determinando-se, inclusive o teor de finos. Foram desenvolvidos dois tipos de argamassas, uma hidráulica e outra mista. $\mathrm{O}$ agregado reciclado foi utilizado em substituição ao agregado natural, nas proporções de $30 \%$ e 60\%, para os dois tipos de argamassa. As características das argamassas nos estados plástico e endurecido foram determinadas e as argamassas foram classificadas segundo a norma de especificação para argamassas de assentamento e revestimento. Foi verificada a correlação entre o teor de finos da argamassa e as características nos estados plástico e endurecido, para a maioria das características observadas. No estado plástico, o aumento da porcentagem de substituição do agregado natural pelo reciclado produziram uma redução da massa especifica da ordem de 4\% para os dois tipos de argamassa, e a capacidade de retenção de água apresentou comportamento inverso, as argamassas mistas apresentaram melhores resultados neste quesito. No estado endurecido, as resistências tração e à compressão tiveram resultados menores em função do aumento da substituição do agregado natural pelo reciclado A argamassa hidráulica apresentou melhor desempenho que a argamassa mista quando classificada conforme a NBR13281.

Palavras-chave: Agregado reciclado, Argamassa para revestimento, Resíduos, Construção civil.

\section{ABSTRACT}

Concern to the environment, due to the large amount of construction waste that is improperly disposed, encouraged the processing of these with the intention of returning them to the productive system. Studies to intensify the reuse of construction waste have intensified recently, developing standards for the production, evaluation and use of recycled aggregates, for which consumption is still incipient. For the development of the work, the characteristics of the recycled and natural aggregates were determined, including fine content. Two types of mortars were developed, one hydraulic and the other mixed. The recycled aggregate was used to replace the natural aggregate, in the proportions of $30 \%$ and $60 \%$, for both types of mortar. The characteristics of the mortars in the fresh and hardened states were determined and the mortars were classified according to the specification standard for laying and coating mortars. The correlation between the fines contents of the mortar and the characteristics in the plastic and hardened states was verified for most of the observed characteristics. In the plastic state, the increase in the percentage of substitution of natural aggregate by the 
recycled produced a specific mass reduction of the order of $4 \%$ for both types of mortar, and the water retention capacity presented an inverse behavior, mixed mortars presented better results in this aspect. In the hardened state, the tensile and compressive strengths had lower results due to the increase in the substitution of the natural aggregate by recycling. The hydraulic mortar presented better performance than the mixed mortar when classified according to NBR13281.

Keywords: recycled aggregate, rendering mortar, residues, civil construction.

\section{INTRODUÇÃO}

A cadeia da construção civil, assim como as demais cadeias industriais, está estruturada em torno de uma cadeia de produção linear. O desafio do desenvolvimento sustentável é mudar o paradigma da produção industrial de um modelo linear para um modelo de produção de ciclo fechado, onde os resíduos retornam ao processo produtivo [1]. Segundo a Resolução CONAMA no 307/2012 do Conselho Nacional do Meio Ambiente [2], resíduos da construção civil são os provenientes de construções, reformas, reparos e demolições de obras e os resultantes da preparação e da escavação de terrenos, comumente chamados de entulhos de obras ou caliça. Segundo CÓRDOBA [3], aproximadamente $90 \%$ dos resíduos da construção civil (RCC) são classificados como inerte, porém, por possuir composição bastante heterogênea, pode possuir também materiais que o caracterizem como resíduo perigoso, como tintas, impermeabilizantes e amianto.

Porém o grande problema dos RCC não advém de sua periculosidade, mas sim do impacto causado pelo excessivo volume gerado. Volume esse que, quando destinado a aterros sanitários pode reduzir sua vida útil, e quando depositado em locais impróprios degrada o meio ambiente urbano, podendo comprometer a paisagem, o tráfego de pedestres e de veículos, a drenagem urbana, além de propiciarem a multiplicação de vetores de doenças, [4].

A construção civil gera em média $510 \mathrm{~kg} / \mathrm{hab} / \mathrm{ano}$, [5]. Além de consumir uma grande quantidade de materiais, a construção civil também causa impactos por sua franca expansão em grandes regiões do mundo, inclusive no Brasil. Não se pode parar de construir casas, hospitais, melhorar os transportes. Então, um dos grandes desafios da construção civil é diminuir o desperdício de materiais, [6].

Em levantamentos feitos para seis cidades brasileiras, [7, 8,3], são apontados os montantes relativos às frações do resíduo que podem ser reciclados e, portanto, podem ser utilizados como agregados na própria indústria da construção civil. Verifica-se que o percentual de resíduos que poderiam ser britados e utilizados como agregado na própria indústria da construção civil varia entre $86 \%$ e $99 \%$.

Os produtos da reciclagem possuem uma série de aplicações como pavimentação e concreto sem fins estruturais. Os usos recomendados pela Associação Brasileira para Reciclagem de Resíduos da Construção Civil e Demolição [9], são:

Areia: produção de argamassa de assentamentos, blocos e tijolos de vedação.

Pedrisco: fabricação de artefatos de concreto, como mesas e bancos de praça, pisos intertravados e manilhas de esgoto.

Brita: obras de drenagem e produção de concretos não-estruturais.

Bica corrida: base e sub-base de pavimentação, reforço e subleito de pavimentos e regularização de vias não pavimentadas.

Rachão: obras de pavimentação, drenagem e terraplanagem.

As características dos agregados reciclados para utilização em pavimentação e para produção de concreto, sem função estrutural são especificadas pela NBR 15116, [10]. Essa norma técnica ainda classifica os agregados reciclados em agregado de resíduo de concreto (ARC) e agregado reciclado misto (ARM).

As argamassas de revestimento, segundo SCATAMBURLO, [11] possui importante função na melhoria da qualidade de vida, já que concebe a impermeabilização da alvenaria, inibindo assim a proliferação de ácaros e fungos e a infiltração de água, para avaliação de sua qualidade são determinadas características físicas e mecânicas.

Como forma de ampliar o consumo de agregado reciclado estudos tem sido realizados para sua inclusão na produção de argamassas. Como exemplo ARAÚJO [12] que analisou o desempenho de argamassa de revestimento produzido com agregados reciclados em Natal (RN), incluindo a caracterização química, física e microestrutural dos agregados reciclados.

Para MIRANDA e SELMO [13], o parâmetro " materiais totais mais finos do que $75 \mu \mathrm{m}$ " na mistura seca é um parâmetro melhor para o controle da fissuração potencial das argamassas do que a relação água / cimento, sendo esta uma indicação importante de que a distribuição dos tamanhos de poros gerados pela pre- 
sença de finos nas misturas tem um efeito mais elevado na contração de secagem do que na porosidade introduzida pela própria razão água / cimento propriamente dita.

RUDNITSKI et al [14] estudou o comportamento de argamassa mista com dois tipos de agregado reciclado, um proveniente de resíduos cerâmicos e outro de resíduos cimenticios. A resistência à tração na flexão e à compressão axial das argamassas com agregado reciclado cerâmico apresentaram resultados superiores as argamassas com agregado reciclado cimenticio.

Estudos desenvolvidos por MARTÍNEZ et al.[15], em argamassas produzidas com agregado reciclado, apresentaram menor massa específica e maior capacidade de absorção de água. Este pesquisador trabalhou com três tipos de agregados reciclados, o cerâmico, o misto e o de concreto. O agregado natural foi substituído em três diferentes proporções: 50\%, 75\% e 100\%. Em cada proporção foram adotados traços de 1:3 e 1:4 em peso seco. Os resultados apontam uma diminuição da resistência a medida que se aumenta a porcentagem de substituição do agregado natural pelo reciclado, sendo o índice de redução da resistência menor quando da utilização do agregado reciclado de concreto.

SILVA, [16] obteve coeficiente de absorção de água por capilaridade entre20 a $40 \mathrm{~g} /\left(\mathrm{dm}^{2} \mathrm{~min}^{1 / 2}\right)$, para traço de argamassa mista (1:3:8), o qual foi classificado como classe C6 conforme a norma NBR 13281.

LEDESMA et al., [17], apresentaram resultados que variaram de $6,0 \mathrm{~g} /\left(\mathrm{dm}^{2} \mathrm{~min}^{1 / 2}\right)$ a 11,2 $\mathrm{g} /\left(\mathrm{dm}^{2} \mathrm{~min}^{1 / 2}\right)$ na argamassa com0\% e $100 \%$ de substituição do agregado natural pelo reciclado, apresentando também um aumento da capacidade de absorção em função do aumento de substituição

LEDESMA et al.[17] e LEDESMA et al.[18] também demonstram que as argamassas hidráulicas produzidas com agregados finos reciclados apresentam menor massa específica em função do aumento da porcentagem de substituição do agregado fino pelo agregado fino reciclado. Foi observada também uma redução da resistência à compressão e um aumento da capacidade de absorção de agua por capilaridade.

SAMIEI et al. [19] trabalharam com argamassas hidráulicas e mistas, utilizando traços de 1:3 e 1:1:6 respectivamente. Para cada argamassa foram utilizados os seguintes percentuais de substituição do agregado natural fino: $0 \%, 25 \%, 50 \%, 75 \%$ e $100 \%$. Os resultados também apontaram queda da resistência e da massa especifica em função do aumento da porcentagem de substituição.

SANTOS [20] estudou o comportamento de argamassas executadas com resíduos no estado plástico observando que o teor de ar incorporado pode ser influenciado pelo uso de aditivos incorporadores ou mesmo pelo tempo de mistura da argamassa, os valores de teor de ar incorporado obtido foram da ordem de $40 \%$, porém a variação deste índice com a substituição da areia pelo resíduo foi inferior a $2 \%$. Já em relação a capacidade de absorção de água por capilaridade, o autor evidencia o aumento da absorção em função do aumento do teor de substituição do agregado natural pelo resíduo.

BREITENBACH [21] em um estudo sobre a incorporação de resíduos em argamassas mistas verificou que ocorreu aumento da capacidade de retenção de água quando do aumento da substituição da areia pelo resíduo, e concluiu que o aumento da capacidade de retenção de agua se deu porque o resíduo apresentou maior teor de finos e consequentemente maior área especifica dos materiais constituintes.

Visando buscar novas possibilidades para a utilização dos resíduos da construção civil (RCC), por meio do processo de reciclagem, o presente trabalho teve como objetivo verificar a possibilidade de utilização do agregado reciclado miúdo na produção de argamassas. Como o agregado reciclado apresenta alto teor de finos, buscou-se verificar também a influência do teor deste material nas propriedades das argamassas no estado plástico e endurecido. As argamassas produzidas foram analisadas e classificadas segundo os requisitos da norma NBR 13281, [22].

\section{MATERIAIS E MÉTODOS}

A metodologia desta pesquisa é experimental e buscou verificar as influências dos agregados miúdos oriundos do RCC em substituição ao agregado miúdo natural na produção de argamassas hidráulica e mista para revestimento. As proporções de substituição do agregado natural (AN) pelo agregado miúdo reciclado (ARM), estudado foram $0 \%, 30 \%$ e, $60 \%$. Foram determinados dois traços de argamassa, um hidráulico e outro misto, baseado em MILITO [23] e MIRANDA [24] e a sua preparação, tanto da argamassa hidráulica como da mista, foi feita conforme especificado pela NBR 13276 [25].

Após a caracterização dos agregados natural e reciclado e da definição dos traços de argamassa hidráulica e mista foi realizada a caracterização das argamassas nos estados plástico e endurecido e feita a correlação entre o teor de finos presente na argamassa e as características determinadas. O delineamento experimental é apresentado na Tabela 1. 
Tabela 1: Delineamento experimental do número de repetições/amostras

\begin{tabular}{|c|c|c|c|c|c|c|c|}
\hline \multirow{2}{*}{ Estado } & \multirow{2}{*}{ Característica } & \multicolumn{3}{|c|}{ Argamassa Hidráulica } & \multicolumn{3}{|c|}{ Argamassa Mista } \\
\hline & & Ref & 30 & 60 & Ref & 30 & 60 \\
\hline \multirow{4}{*}{$\begin{array}{l}\frac{0}{0} \\
\frac{0}{5} \\
\frac{\pi}{0} \\
\frac{0}{0} \\
\frac{\pi}{4} \\
w\end{array}$} & $\begin{array}{c}\text { Consistência NBR } 13276 \\
{[25]}\end{array}$ & 1 & 1 & 1 & 1 & 1 & 1 \\
\hline & $\begin{array}{c}\text { Massa Especifica NBR } \\
13278[26] \\
\end{array}$ & 3 & 3 & 3 & 3 & 3 & 3 \\
\hline & $\begin{array}{c}\text { Teor de ar incorporado } \\
\text { NBR } 13278[26]\end{array}$ & 3 & 3 & 3 & 3 & 3 & 3 \\
\hline & $\begin{array}{l}\text { Capacidade de retenção } \\
\text { de água NBR } 13277 \text { [27]. }\end{array}$ & 1 & 1 & 1 & 1 & 1 & 1 \\
\hline \multirow{4}{*}{ 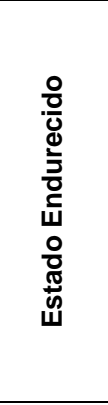 } & $\begin{array}{c}\text { Resistência a Compressão } \\
\text { Axial } 28 \text { dias NBR } \\
13279,[28] \\
\end{array}$ & 6 & 6 & 6 & 6 & 6 & 6 \\
\hline & $\begin{array}{c}\text { Resistência a Tração na } \\
\text { flexão } 28 \text { dias NBR } \\
13279,[28] \\
\end{array}$ & 3 & 3 & 3 & 3 & 3 & 3 \\
\hline & $\begin{array}{c}\text { Absorção de água por } \\
\text { capilaridade NBR 15259, } \\
{[29]} \\
\end{array}$ & 3 & 3 & 3 & 3 & 3 & 3 \\
\hline & $\begin{array}{c}\text { Densidade de massa apa- } \\
\text { rente NBR } 13280,[30]\end{array}$ & 3 & 3 & 3 & 3 & 3 & 3 \\
\hline
\end{tabular}

Os materiais utilizados foram o cimento de alto forno (CP III); cal hidratada tipo III, areia natural e areia reciclada (ARM) proveniente de unidade recicladora de entulho do município de Campinas, constituído pela britagem de resíduo classe A, conforme resolução CONAMA 307 [2], portanto, constituído de materiais cimentícios e cerâmicos e água potável.

Tabela 2: Características do cimento e da cal hidratada

\begin{tabular}{l|c|c}
\hline Material & Massa especifica $\mathbf{( g / \mathbf { c m } ^ { \mathbf { 3 } } )}$ & Finura \#200 (\%) \\
\hline CP III & 3,03 & 2,1 \\
\hline CH III & 2,40 & 8,0 \\
\hline
\end{tabular}

A avaliação e classificação dos agregados foram baseadas na NBR 15116, [10] para o agregado reciclado e segundo a NBR 7211, [31] para o agregado natural.

A areia natural apresentou modulo de finura de 2,28 e diâmetro máximo de 2,4mm e o agregado reciclado com módulo de finura de 2,21 e diâmetro máximo de 2,4mm sendo ambas classificadas como areia média (zona ótima de utilização).

A Tabela 3 apresenta as características dos agregados, natural e reciclado observa-se que o agregado reciclado apresenta massa especifica $10 \%$ menor que o agregado natural. $\mathrm{O}$ teor de finos e a capacidade de absorção de água do agregado reciclado são muito elevados quando comparados aos do agregado natural, cerca de $350 \%$ e $600 \%$ respectivamente, o que acarretou em maior consumo de água para obtenção da mesma consistência durante o estudo das argamassas.

Tabela 3: Características físicas dos agregados

\begin{tabular}{c|c|c|c|c}
\hline Agregados & $\begin{array}{c}\text { Massa Específica } \\
\left(\mathbf{g} / \mathbf{c m}^{\mathbf{3}}\right)\end{array}$ & $\begin{array}{c}\text { Massa Unitária } \\
\left(\mathbf{g} / \mathbf{c m}^{\mathbf{3}}\right)\end{array}$ & Teor de Finos (\%) & $\begin{array}{c}\text { Capacidade de } \\
\text { Absorção (\%) }\end{array}$ \\
\hline Natural & 2,65 & 1,54 & 7,47 & 1,5 \\
\hline Reciclado & 2,38 & 1,24 & 26,64 & 10,5 \\
\hline
\end{tabular}

Baseados nessas características foram determinados os traços em massa adotados para a argamassa mista e hidráulica, houve a necessidade de alterar a relação água/cimento para atendimento ao índice de consistência de $260 \pm 5 \mathrm{~mm}$ especificado pela NBR 13749, [32].

A Tabela 4 apresenta os traços unitários em massa, a relação agua/cimento (a/c), o consumo de cimento $(\mathrm{Cc})$ e o teor de finos (TF) da argamassa. 
Tabela 4: Traços unitários em massa

\begin{tabular}{|c|c|c|c|c|c|c|c|c|}
\hline \multicolumn{2}{|c|}{ Traço } & Cimento & Cal & AN & ARM & $a / c$ & $\mathrm{Cc}\left(\mathrm{kg} / \mathrm{m}^{3}\right)$ & TF (\%) \\
\hline \multirow{3}{*}{ 离 } & $\mathrm{HO}$ & 1 & - & 6,10 & - & 1,21 & 261,7 & 20,2 \\
\hline & $\mathrm{H} 30$ & 1 & - & 4,27 & 1,83 & 1,45 & 241,5 & 25,2 \\
\hline & H60 & 1 & - & 2,44 & 3,66 & 1,87 & 216,0 & 30,1 \\
\hline \multirow{3}{*}{$\frac{\pi}{\frac{\pi}{2}}$} & M0 & 1 & 2 & 5,90 & --- & 1,50 & 207,5 & 36,7 \\
\hline & M30 & 1 & 2 & 4,10 & 1,70 & 1,60 & 206,5 & 40,7 \\
\hline & M60 & 1 & 2 & 2,40 & 3,40 & 1,90 & 203,9 & 44,4 \\
\hline
\end{tabular}

(AN) Agregado natural; (ARM) Agregado reciclado misto; (a/c) Relação agua/cimento; (Cc) Consumo de cimento; (TF) Teor de finos

O Teor de finos em cada traço de argamassa (TF) foi calculado pela Equação 1 adaptado de MIRAN-

DA,[24]. Observa-se que o teor de finos é maior para argamassa mista devido a presença da cal hidratada.

$T F=\frac{\text { Mcim } * \% \mathrm{fcim}+\mathrm{Mcal} * \% \mathrm{fcal}+\mathrm{MAN} * \% \mathrm{fAN}+\mathrm{MARM} * \% \mathrm{fARM}}{\mathrm{Mcim}+\mathrm{Mcal}+\mathrm{MAN}+\mathrm{MARM}}$

Equação 1

Onde:

$\mathrm{TF}$ - \% total de finos de dimensão inferior à peneira $0,075 \mathrm{~mm}$ na argamassa anidra;

$\%$ fcim - \% total de finos de dimensão inferior à peneira $0,075 \mathrm{~mm}$ no cimento;

$\%$ fcal - \% total de finos de dimensão inferior à peneira $0,075 \mathrm{~mm}$ na cal;

$\%$ fAN - \% total de finos de dimensão inferior à peneira $0,075 \mathrm{~mm}$ na areia;

\%fARM - \% total de finos de dimensão inferior à peneira $0,075 \mathrm{~mm}$ no agregado reciclado cimentício;

Mcim - massa de cimento

Mcal - massa de cal

MAN - massa de areia natural;

MARM - massa de agregado reciclado cimentício.

$\mathrm{Na}$ análise dos resultados foi obtida a média das características das argamassas no estado endurecido e no estado plástico, estas foram comparadas entre si em função do tipo de argamassa, hidráulica ou mista, e em relação ao teor de finos da argamassa e à porcentagem de substituição do agregado natural pelo reciclado, $0 \%, 30 \%$ e $60 \%$.

Foram feitas análises de correlação entre o teor de finos de cada traço e todas as características determinadas, quando o coeficiente de correlação de Pearson, indicado por $\mathrm{R}^{2}$ for superior a 0,6 indica que existe forte interdependência entre as variáveis [33]. Foi feita também a classificação das argamassas conforme a NBR 13281 [22], a qual esta apresentada, de forma resumida, na tabela 5.

Tabela 5: Resumo das faixas de classificação conforme NBR 13281 [22]

\begin{tabular}{|c|c|c|c|c|c|c|}
\hline \multirow[b]{2}{*}{$\begin{array}{l}\text { Classi- } \\
\text { ficação }\end{array}$} & \multicolumn{4}{|c|}{ Estado endurecido } & \multicolumn{2}{|c|}{ Estado plástico } \\
\hline & $\begin{array}{l}\text { Resistencia à } \\
\text { compressão } \\
\text { (MPa) (P) }\end{array}$ & $\begin{array}{c}\text { Densidade de- } \\
\text { massa } \\
\left(\mathbf{k g} / \mathrm{m}^{3}\right)(\mathrm{M})\end{array}$ & $\begin{array}{c}\text { Resistencia à } \\
\text { tração na fle- } \\
\text { xão } \\
(\mathrm{MPa})(\mathrm{R})\end{array}$ & $\begin{array}{l}\text { Absorção por } \\
\text { capilaridade } \\
\left(\mathrm{g} / \mathrm{dm}^{2} \cdot \min ^{1 / 2}\right) \text { (C) }\end{array}$ & $\begin{array}{c}\text { Densidade de } \\
\text { massa } \\
\left(\mathrm{kg} / \mathrm{m}^{3}\right)(\mathrm{D})\end{array}$ & $\begin{array}{c}\text { Retenção } \\
\text { de água } \\
\text { (\%) (U) }\end{array}$ \\
\hline 1 & $\begin{array}{c}\text { P1 } \\
\leq 2,0 \\
\end{array}$ & $\begin{array}{l}\text { M1 } \\
\geq\end{array}$ & $\begin{array}{c}\mathrm{R} 1 \\
\leq 1,5 \\
\end{array}$ & $\begin{array}{c}\mathrm{C} 1 \\
\leq 1,5 \\
\end{array}$ & $\begin{aligned} & \text { D1 } \\
& \geq 1400 \\
&\end{aligned}$ & $\begin{array}{c}\mathrm{U} 1 \\
\geq 78 \\
\end{array}$ \\
\hline 2 & $\begin{array}{c}\mathrm{P} 2 \\
1,5 \text { a } 3,0\end{array}$ & $\begin{array}{c}\mathrm{M} 2 \\
1000 \text { a } 1400\end{array}$ & $\begin{array}{c}\mathrm{R} 2 \\
1,0 \text { a } 2,0\end{array}$ & $\begin{array}{c}\mathrm{C} 2 \\
1,0 \text { a } 2,5\end{array}$ & $\begin{array}{c}\text { D2 } \\
1200 \text { a } 1600\end{array}$ & $\begin{array}{c}\mathrm{U} 2 \\
72 \text { a } 85\end{array}$ \\
\hline 3 & $\begin{array}{c}\text { P3 } \\
2,5 \text { a } 4,5 \\
\end{array}$ & $\begin{array}{c}\text { M3 } \\
1200 \text { a } 1600 \\
\end{array}$ & $\begin{array}{c}\mathrm{R} 3 \\
1,5 \text { a } 2,7 \\
\end{array}$ & $\begin{array}{c}\mathrm{C} 3 \\
2,0 \mathrm{a} 4,0 \\
\end{array}$ & $\begin{array}{c}\text { D3 } \\
1400 \text { a } 1800 \\
\end{array}$ & $\begin{array}{c}\text { U3 } \\
\text { 80a } 90 \\
\end{array}$ \\
\hline 4 & $\begin{array}{c}\mathrm{P} 4 \\
4,0 \text { a } 6,0\end{array}$ & $\begin{array}{c}\text { M4 } \\
1400 \text { a } 1800\end{array}$ & $\begin{array}{c}\mathrm{R} 4 \\
2,0 \text { a } 3,5\end{array}$ & $\begin{array}{c}\mathrm{C} 4 \\
3,0 \text { a } 7,0\end{array}$ & $\begin{array}{c}\text { D4 } \\
1600 \text { a } 2000 \\
\end{array}$ & $\begin{array}{c}\mathrm{U} 4 \\
86 \text { e } 94\end{array}$ \\
\hline 5 & $\begin{array}{c}\text { P5 } \\
5,5 \text { a } 9,0\end{array}$ & $\begin{array}{c}\text { M4 } \\
1600 \text { a } 2000\end{array}$ & $\begin{array}{c}\text { R5 } \\
2,7 \text { a } 4,5\end{array}$ & $\begin{array}{c}\text { C5 } \\
5,0 \text { a } 12,0\end{array}$ & $\begin{array}{c}\text { D5 } \\
1800 \text { a } 2200 \\
\end{array}$ & $\begin{array}{c}\text { U5 } \\
91 \text { a } 97\end{array}$ \\
\hline 6 & $\begin{array}{c}\text { P6 } \\
\geq 8,0 \\
\end{array}$ & $\begin{array}{c}\text { M6 } \\
\geq 1800 \\
\end{array}$ & $\begin{array}{c}\mathrm{R} 6 \\
\geq 3,5 \\
\end{array}$ & $\begin{array}{c}\text { C6 } \\
\geq 10,0 \\
\end{array}$ & $\begin{array}{c}\text { D6 } \\
\geq 2000 \\
\end{array}$ & $\begin{array}{c}\text { U6 } \\
95 \mathrm{a} 100 \\
\end{array}$ \\
\hline
\end{tabular}


Apesar da norma NBR 13281 [22] exigir que venha impressa nas embalagens das argamassas industrializadas a indicação do tipo de argamassa, (revestimento interno, revestimento externo, assentamento de alvenaria de vedação, etc.) não deixa claro o requisito e a classe que deve ser exigida para cada tipo de utilização, [16].

\section{RESULTADOS E DISCUSSÃO}

Neste tópico são apresentados os resultados dos ensaios realizados separados em dois tópicos conforme os estados da argamassa, plástico e endurecido.

\subsection{Características das argamassas no estado plástico}

\subsubsection{Densidade de massa aparente}

A Tabela 6 apresenta os resultados de densidade de massa aparente obtidas para todos os traços de argamassa. Observa-se que a medida que se aumenta a porcentagem de substituição do agregado natural pelo reciclado, a massa especifica diminui para os dois tipos de argamassa, hidráulica e mista. Essa tendência de redução da massa especifica se justifica pela menor massa especifica do agregado reciclado $\left(2,38 \mathrm{~g} / \mathrm{cm}^{3}\right)$ em relação ao agregado natural $\left(2,65 \mathrm{~g} / \mathrm{cm}^{3}\right)$. Baseado na NBR 13281, [22] as argamassas foram classificadas, as argamassas hidráulicas e mistas se enquadraram na classe D5, com massa especifica no estado plástico entre 1800 e $2200 \mathrm{~kg} / \mathrm{m}^{3}$.

Tabela 6: Resultados de massa específica

\begin{tabular}{c|c|c}
\hline \multirow{2}{*}{ Traço } & Argamassa Hidráulica & Argamassa Mista \\
\cline { 2 - 3 } & $\begin{array}{c}\text { Densidade de massa apa- } \\
\text { rente } \mathbf{( g / \mathbf { c m } ^ { 3 } )}\end{array}$ & $\begin{array}{c}\text { Densidade de massa apa- } \\
\text { rente }\left(\mathbf{g} / \mathbf{c m}^{3}\right)\end{array}$ \\
\hline $0 \%$ & 2,000 & 2,050 \\
\hline $30 \%$ & 1,980 & 2,020 \\
\hline $60 \%$ & 1,910 & 1,942 \\
\hline
\end{tabular}

Observou-se que existe forte correlação entre o teor de finos e a massa específica, uma vez que o teor de finos do agregado reciclado (26,64\%) é maior que do agregado natural (7,47\%). O gráfico apresentado na Figura 1 mostra a linha de tendência e os coeficientes de correlação para as argamassas hidráulica e mista.

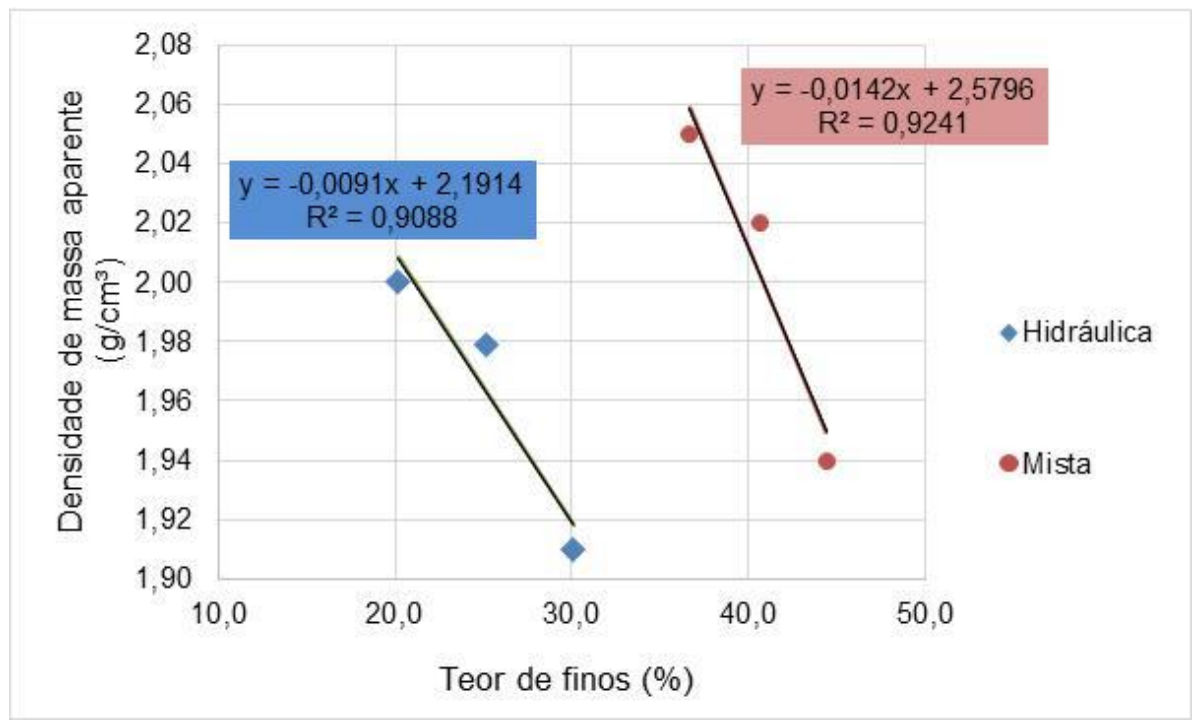

Figura 1: Correlação entre teor de finos e densidade de massa aparente.

\subsubsection{Teor de ar incorporado}

O teor do ar incorporado influencia na massa especifica e na consistência das argamassas, normalmente quanto maior o teor de ar incorporado menor a massa especifica e maior a plasticidade, porém a NBR 13281 
[22], não especifica faixas de valores para classificar as argamassas quanto ao teor de ar incorporado. A tabela 7 apresenta os resultados de teor de ar incorporado obtido para as argamassas hidráulica e mista. Observase que para as argamassas hidráulicas o teor de ar incorporado é menor que para argamassas mistas, e em ambas o teor obtido é inferior aos teores obtidos por SANTOS [20].

Tabela 7: Resultados de teor de ar incorporado

\begin{tabular}{c|c|c}
\hline \multirow{2}{*}{ Traço } & Argamassa Hidráulica & Argamassa Mista \\
\cline { 2 - 3 } & Teor de ar (\%) & Teor de ar (\%) \\
\hline $0 \%$ & 3,33 & 5,75 \\
\hline $30 \%$ & 2,68 & 6,78 \\
\hline $60 \%$ & 2,79 & 6,47 \\
\hline
\end{tabular}

A Figura 2 apresenta os resultados referentes ao teor do ar incorporado nas argamassas hidráulicas e mistas em função do teor de finos da mistura observa-se que existe correlação entre o teor de ar incorporado e o teor de finos.

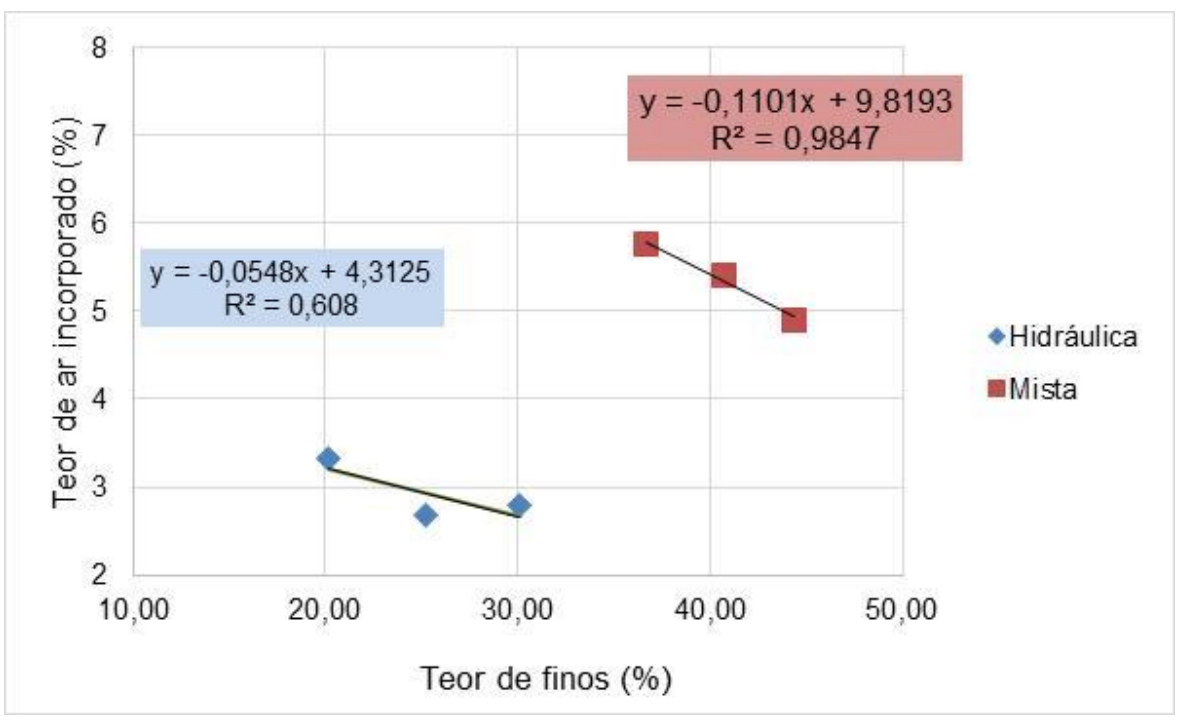

Figura 2: Correlação entre teor de finos e Teor de ar incorporado.

\subsubsection{Capacidade de retenção de água}

Com relação à capacidade de retenção de água, para a argamassa hidráulica observou-se que à medida que se aumenta a porcentagem de substituição do agregado natural pelo reciclado, a capacidade de retenção de água aumenta. Os valores são apresentados na tabela 8. Segundo a NBR 13281, [22] as argamassas hidráulicas se enquadraram na classe U4, com retenção de água entre 86 e 94\%, as demais argamassas mistas enquadram-se na classe U5.

Tabela 8: Resultados de capacidade de retenção de água

\begin{tabular}{c|c|c}
\hline \multirow{2}{*}{ Traço } & Argamassa Hidráulica & Argamassa Mista \\
\cline { 2 - 3 } & Retenção de água (\%) & Retenção de água (\%) \\
\hline $0 \%$ & 88,24 & 95,77 \\
\hline $30 \%$ & 91,16 & 96,36 \\
\hline $60 \%$ & 91,36 & 96,99 \\
\hline
\end{tabular}

É importante lembrar que a retenção de água pela argamassa é um fator que confere maior qualidade para a argamassa, uma vez que evita a evaporação da água de amassamento e minimiza o efeito de perda de água devido à sucção do substrato, nestas condições, contribui para a hidratação do cimento, resultando maior resistência do revestimento. Um dos fatores que podem gerar maior capacidade de retenção de água é a ocorrência de maior área especifica dos materiais constituintes, o que ocorreu para as argamassas aqui analisadas, pois com o aumento do teor de substituição, as argamassas apresentaram maior teor de finos e consequentemente maior área especifica, aumentando a capacidade de retenção de água, apresentando o mesmo 
comportamento obtido por [21]. As argamassas mistas apresentaram maior valor de capacidade de retenção de água, no entanto o aumento do teor de finos foi menos significativo para essas argamassas (1,3\%) do que para as argamassas hidráulicas, que apresentaram aumento da capacidade de retenção de água de 3,5\%.

A figura 3 mostra a linha de tendência e os coeficientes de correlação para as argamassas hidráulica e mista em relação à capacidade de retenção de água, observa-se forte correlação entre o teor de finos e a capacidade de retenção de água $\left(\mathrm{R}^{2}=0,803\right)$ para a argamassa hidráulica e para a argamassa mista $\left(\mathrm{R}^{2}=0,998\right)$.

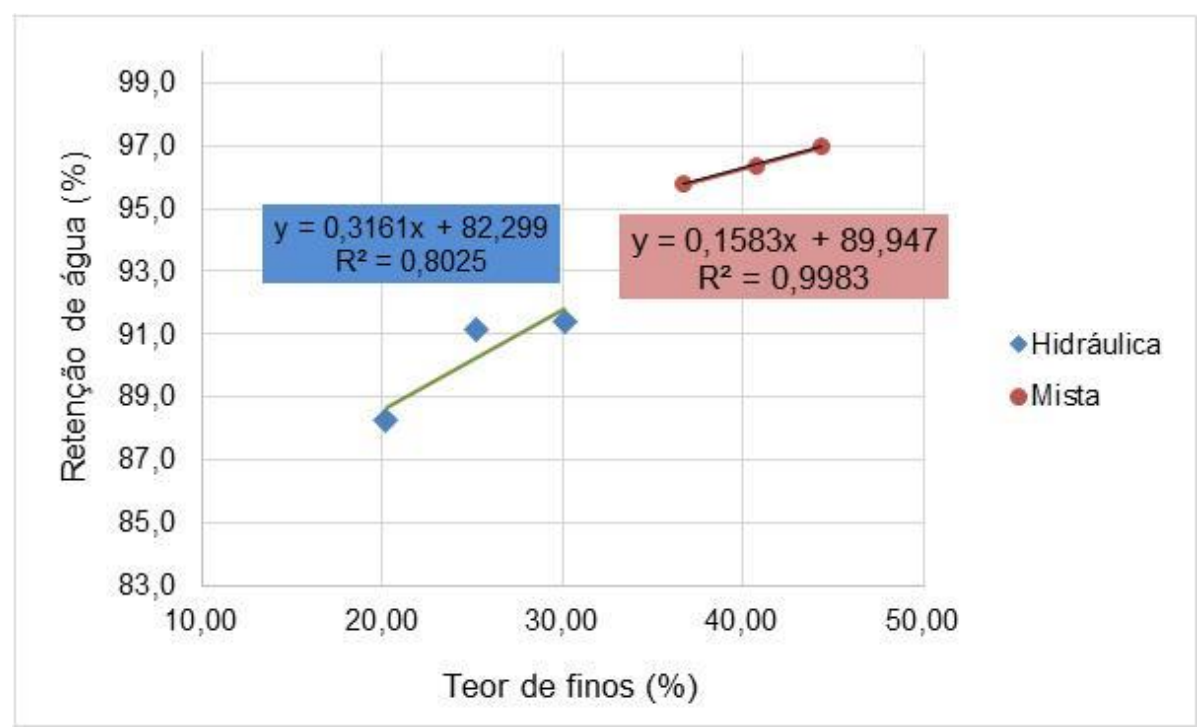

Figura 3: Correlação entre teor de finos e capacidade de retenção de água

A Tabela 9 apresenta os coeficientes de correlação $\left(\mathrm{R}^{2}\right)$ de todas as características no estado plástico em relação ao teor de finos. Conforme se observa, todas elas são estatisticamente influenciadas pelo teor de finos da argamassa, tanto para a argamassa hidráulica como para a argamassa mista.

Tabela 9: Coeficientes de Correlação $\left(\mathrm{R}^{2}\right)$ entre Teor de Finos e variáveis no estado plástico

\begin{tabular}{c|c|c}
\hline & Argamassa Hidráulica & Argamassa Mista \\
\hline Massa Especifica & 0,909 & 0,924 \\
\hline Teor de Ar Incorporado & 0,608 & 0,985 \\
\hline Retenção de água & 0,803 & 0,998 \\
\hline
\end{tabular}

\subsection{Características das argamassas no estado endurecido}

\subsubsection{Densidade de massa aparente}

A Tabela 10 apresenta os valores médios da determinação da densidade massa aparentes e os respectivos desvios padrão. O valor do desvio padrão $(\mathrm{Sd}$ ) é baixo, mostrando que o resultado dos ensaios foi confiável. Não se observa diferenças significativas entre os valores de densidade de massa aparente obtidos para as argamassas mistas e hidráulicas. A tendência de redução da densidade de massa aparente com o aumento da porcentagem de substituição se deve a menor massa especifica do agregado reciclado e não ao teor de ar incorporado, uma vez que este apresentou uma tendência de redução em função do aumento da porcentagem de substituição, o que ocorreu para os dois tipos de argamassa, como observado na figura 2.

Os resultados obtidos por SAMIEI et al. [16] foi análogo aos obtidos neste trabalho, mostrando a mesma tendência de decréscimo da densidade aparente no estado endurecido, tanto, para a argamassa hidráulica, quanto da argamassa mista em função do aumento da porcentagem de substituição.

Todas as argamassas hidráulicas e mistas são classificadas como M5 com densidade variando de 1600 $\mathrm{kg} / \mathrm{m}^{3}$ a $2000 \mathrm{~kg} / \mathrm{m}^{3}$ pela classificação da NBR 13281 [22]. 
Tabela 10: Resultados dos ensaios de determinação da densidade de massa aparente

\begin{tabular}{c|c|c|c|c}
\hline \multicolumn{4}{c}{ Densidade de massa aparente $\left(\mathbf{g} / \mathbf{c m}^{3}\right)$} \\
\hline \multirow{2}{*}{ \% Substituição } & \multicolumn{2}{|c}{ Hidráulica } & \multicolumn{2}{c}{ Mista } \\
\cline { 2 - 5 } & Média & Sd & Média & Sd \\
\hline 0 & 1,896 & 0,02 & 1,826 & 0,02 \\
\hline 30 & 1,800 & 0,01 & 1,768 & 0,01 \\
\hline 60 & 1,750 & 0,01 & 1,750 & 0,02 \\
\hline
\end{tabular}

A análise de correlação entre a densidade de massa aparente e o teor de finos da argamassa apontou que existe forte correlação, $\mathrm{R}^{2}$ superior a 0,6 para os dois tipos de argamassa, como pode ser observado na Figura 4.

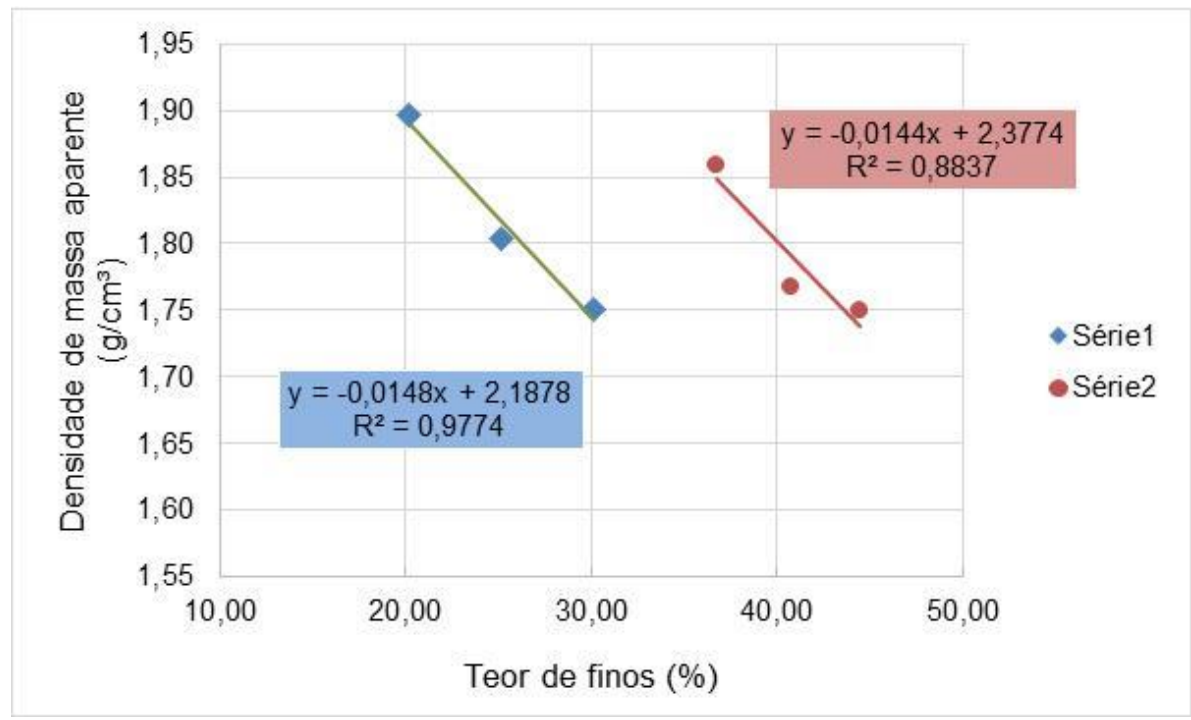

Figura 4: Correlação entre teor de finos e densidade de massa aparente

\subsubsection{Resistência à tração na flexão}

Os resultados dos ensaios de resistência à tração na flexão são apresentados na Tabela 11. Observa-se que as argamassas mistas e hidráulicas apresentam resistências à tração similares e com tendência a sofrer redução em função do aumento da porcentagem de substituição.

Tabela 11: Resultados dos ensaios de resistência à tração na flexão

\begin{tabular}{c|c|c}
\hline \multirow{2}{*}{ \% substituição } & Argamassa Hidráulica & Argamassa Mista \\
\cline { 2 - 3 } & Tração na flexão (MPa) & Tração na flexão (MPa) \\
\hline 0 & 1,98 & 2,25 \\
\hline 30 & 1,86 & 1,95 \\
\hline 60 & 1,66 & 1,79 \\
\hline
\end{tabular}

As resistências à tração na flexão tanto para as argamassas hidráulicas, como para as argamassas mistas são classificadas como R3, pois apresentam valores entre 1,5 MPa e 2,7 MPa.

A análise de correlação entre a resistência à tração e o teor de finos da argamassa apontou que ambos os tipos de argamassa tem forte correlação e o gráfico de correlação é apresentado na figura 5. 


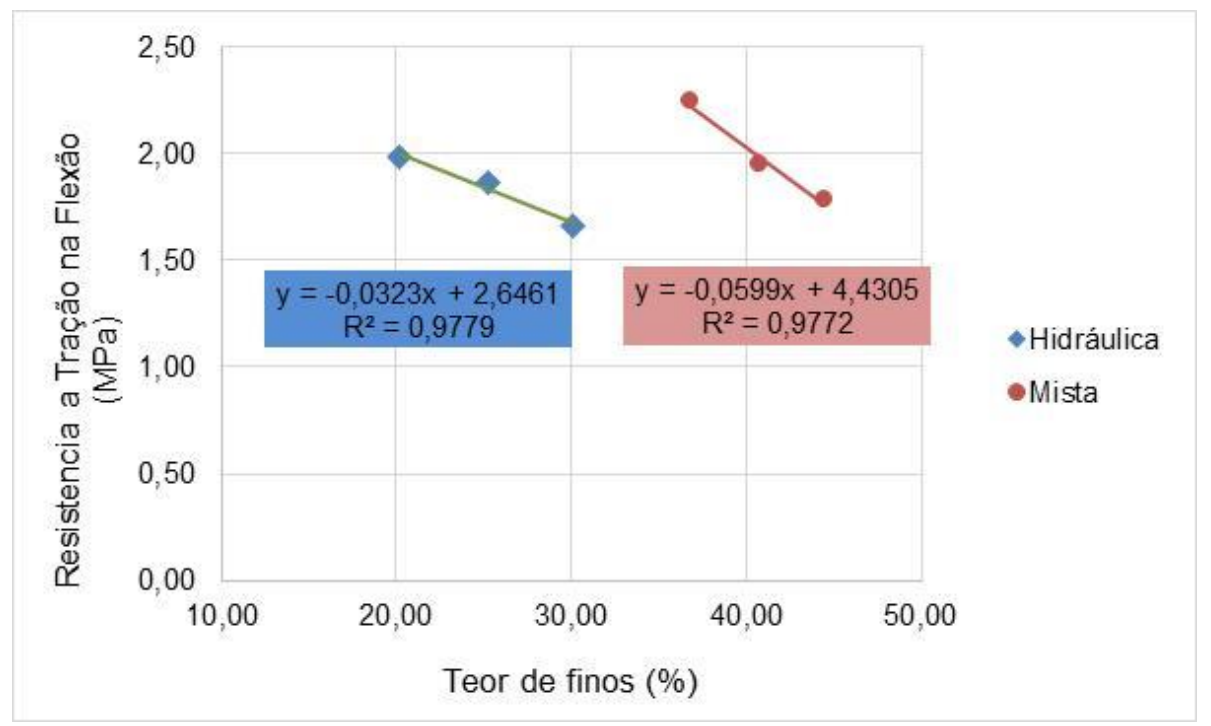

Figura 5: Gráfico de correlação para resistência a tração na flexão

\subsubsection{Resistência à compressão axial}

Observa-se que para a argamassa hidráulica a substituição de $30 \%$ de agregado natural pelo reciclado proporcionou uma redução de $17,7 \%$ e de $20,6 \%$ para o traço com $60 \%$ de substituição, a Tabela 12 apresenta os valores médios.

As argamassas hidráulicas se enquadram na classe P5 de resistência à compressão de acordo com a NBR 13281 [22], os resultados indicam a possibilidade de se preparar uma argamassa com 60\% de substituição com a qualidade da argamassa referência.

Já a argamassa mista sem substituição (0\%) se enquadra na classe P5, e as argamassas mistas com $30 \%$ e $60 \%$ de substituição se enquadram na classe P4 e P3 respectivamente, com valores de resistência diminuindo fortemente.

Tabela 12: Resultados médios dos ensaios de resistência à compressão

\begin{tabular}{|c|c|c|}
\hline \multirow[b]{2}{*}{ \% substituição } & Argamassa Hidráulica & Argamassa Mista \\
\hline & $\begin{array}{c}\text { Compressão axial } \\
(\mathrm{MPa})\end{array}$ & $\begin{array}{c}\text { Compressão axial } \\
(\mathrm{MPa})\end{array}$ \\
\hline 0 & 7,12 & 6,36 \\
\hline 30 & 5,86 & 5,16 \\
\hline 60 & 5,65 & 3,71 \\
\hline
\end{tabular}

A Figura 6 apresenta os resultados médios, relativos à determinação da resistência à compressão axial para as argamassas hidráulicas e mistas em função da porcentagem de finos da argamassa e a correlação entre elas.

Para a argamassa mista, observa-se que, quanto maior o teor de substituição, menor a resistência à compressão, chegando a uma redução máxima de $42 \%$, para o traço com $60 \%$ de substituição em relação ao traço referencia $(0 \%)$. 


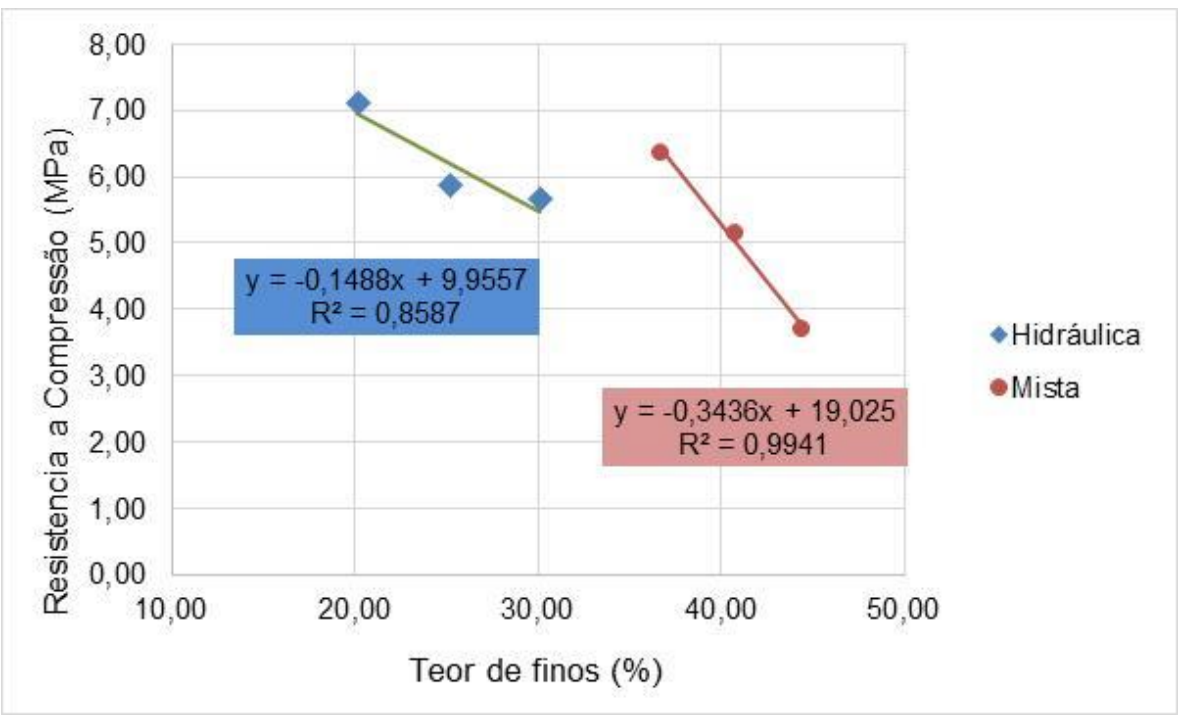

Figura 6: Gráfico de correlação para Resistência à compressão axial

\subsubsection{Capacidade de absorção de água por capilaridade}

A análise de correlação entre a capacidade de absorção de água por capilaridade e o teor de finos da argamassa apontou que o teor de finos afeta, significativamente a essa característica apenas para a argamassa hidráulica, pois o coeficiente de correlação é superior a 0,6 como mostra a figura 7 .

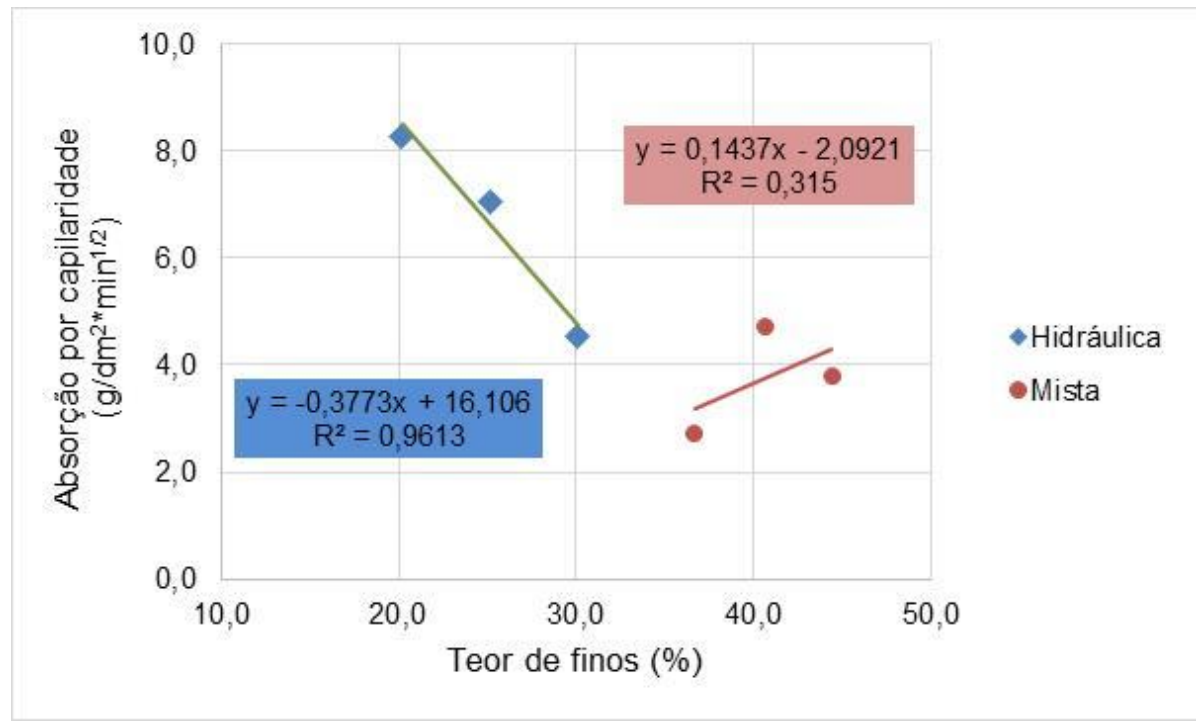

Figura 7: Gráfico de correlação para Absorção de água por capilaridade

A Tabela 13 apresenta as médias do coeficiente de absorção de água por capilaridade obtido para cada tipo de argamassa. As argamassas hidráulicas apresentaram maior capacidade de absorção capilar que as argamassas mistas. Observa-se que, para a argamassa mista, a quantidade de água absorvida aumenta em função do aumento da porcentagem de substituição do agregado natural pelo reciclado, o que vai de encontro aos resultados apresentados por $[16,17,18$ e 20] apesar da variabilidade dos resultados obtidos neste trabalho, que não apontaram uma correlação entre essa característica e o teor de finos.

De acordo com a NBR 13281 [22] as argamassas hidráulicas, referencia (0\%) e com 30\% de substituição são classificadas como C5, a argamassa com $60 \%$ de substituição tem menor capacidade de absorção se enquadrando na classe $\mathrm{C} 4$.

As argamassas mistas com $0 \%$ e $60 \%$ de substituição, se enquadram na classe C3, com capacidade de absorção de água por capilaridade entre 2 e $4 \mathrm{~g} / \mathrm{dm}^{2} \cdot \mathrm{min}^{1 / 2}$ e a argamassa mista com $30 \%$ de substituição é classificada como $\mathrm{C} 4$, com capacidade de absorção de água por capilaridade entre 3 e $7 \mathrm{~g} / \mathrm{dm}^{2} \cdot \mathrm{min}^{1 / 2}$ os resul- 
tados são inferiores aos obtidos por [17].

Tabela 13: Resultados dos ensaios de determinação de absorção de água por capilaridade

\begin{tabular}{c|c|c}
\hline \multirow{2}{*}{ \% substituição } & Argamassa Hidráulica & Argamassa Mista \\
\cline { 2 - 3 } & $\begin{array}{c}\text { Absorção de água por capilaridade } \\
\left(\mathrm{g} / \mathrm{dm}^{2} \cdot \mathrm{min}^{1 / 2}\right)\end{array}$ & $\begin{array}{c}\text { Absorção de água por capilaridade } \\
\left(\mathrm{g} / \mathrm{dm}^{2} \cdot \mathrm{min}^{1 / 2}\right)\end{array}$ \\
\hline 0 & 8,3 & 2,7 \\
\hline 30 & 7,1 & 4,7 \\
\hline 60 & 4,5 & 3,8 \\
\hline
\end{tabular}

O aumento da capacidade de absorção capilar pode ser prejudicial à durabilidade do revestimento, com isso somente o teor de substituição de $30 \%$, tanto para a argamassa hidráulica como para a mista tem o mesmo desempenho que a argamassa referência.

No estado endurecido todas as características foram correlacionadas com o teor de finos da argamassa apresentando forte correlação conforme se observa pelos valores de $\mathrm{R}^{2}$ apresentados na tabela 14 .

Tabela 14: Coeficientes de correlação entre teor de finos e variáveis no estado endurecido $\left(\mathrm{R}^{2}\right)$

\begin{tabular}{c|c|c}
\hline Características & Argamassa Hidráulica & Argamassa Mista \\
\hline Tração na Flexão & 0,977 & 0,977 \\
\hline Compressão Axial & 0,859 & 0,994 \\
\hline Massa Específica & 0,977 & 0,883 \\
\hline Absorção por Capilaridade & 0,961 & 0,315 \\
\hline
\end{tabular}

Um resumo das classificações das argamassas para cada uma das características avaliadas conforme a NBR 13281 [22] é apresentada na tabela 15.

Tabela 15: Resumo das classificações das argamassas conforme NBR 13281 [22]

\begin{tabular}{c|c|c|c|c|c|c}
\hline Traço & $\begin{array}{c}\text { Resistência } \\
\text { àCompres- } \\
\text { são axial } \\
\text { (P) }\end{array}$ & $\begin{array}{c}\text { Densidade de } \\
\text { massa aparente } \\
\text { Endurecido } \\
\text { (M) }\end{array}$ & $\begin{array}{c}\text { Resistência à } \\
\text { Tração na flexão } \\
\text { (R) }\end{array}$ & $\begin{array}{c}\text { Absorção por } \\
\text { capilaridade } \\
\text { (C) }\end{array}$ & $\begin{array}{c}\text { Densidade de } \\
\text { massa aparente } \\
\text { Plástico } \\
\text { (M) }\end{array}$ & $\begin{array}{c}\text { Retenção } \\
\text { de água } \\
\text { (U) }\end{array}$ \\
\hline H0 & P5 & M5 & R3 & C5 & D5 & U4 \\
\hline H30 & P5 & M5 & R3 & C5 & D5 & U4 \\
\hline H60 & P5 & M5 & R3 & C4 & D5 & U4 \\
\hline M0 & P5 & M5 & R3 & C3 & D5 & U5 \\
\hline M30 & P4 & M5 & R3 & C4 & D5 & U5 \\
\hline M60 & P3 & M5 & R3 & C3 & D5 & U5 \\
\hline
\end{tabular}

\section{CONCLUSÕES}

De acordo com os materiais utilizados e ensaios executados, foi possível chegar as seguintes conclusões:

- O aumento do teor de finos resultou em argamassas mais trabalháveis.

- Para as argamassas hidráulica e mista a substituição do agregado natural pelo reciclado melhorou a capacidade de retenção de água, o que é benéfico, pois contribui para a hidratação do cimento, resultando em maior resistência do revestimento.

- Observou-se uma redução da densidade de massa aparente da argamassa, tanto no estado plástico como no estado endurecido, a medida que se aumenta a porcentagem de substituição, o que se justifica pela menor massa específica do agregado reciclado em relação ao agregado natural.

- Analisando a resistência à compressão, no estado endurecido para argamassas hidráulicas, os resultados indicam a possibilidade de se preparar estas argamassas com diversas porcentagens de substituição, pois a substituição resultou em argamassas que se encontram dentro dos parâmetros normalizados conforme a classificação da NBR 13281, [22]. 
- Analisando a capacidade de absorção por capilaridade das argamassas observou-se que as argamassas mistas tiveram um aumento da absorção em função do aumento do teor de substituição. As argamassas hidráulicas se comportaram de forma inversa.

Em síntese, tendo em vista o comportamento das argamassas analisadas, observa-se que tanto as argamassas hidráulicas como as mistas apresentaram características que se enquadram dentro das classes estabelecidas pela NBR 13281 [22]. São necessários ainda ensaios para determinar a aderência ao substrato e sua permeabilidade em condições de aplicação para avaliar seu desempenho em uso.

\section{AGRADECIMENTOS}

Os autores agradecem à FAPESP pelo Projeto de Auxilio a Pesquisa nº 2014/20486-8.

\section{BIBLIOGRAFIA}

[1] MACHIONE, E.C. Caracterização dos resíduos de construção civil e demolição gerados no município de Colina/SP e uma proposta de gerenciamento e disposição adequada,, Dissertação de M.Sc.,Universidade de Ribeirão Preto, UNAERP, Ribeirão Preto, SP, 2010.

[2] BRASIL. Ministério do Meio Ambiente. Conselho Nacional do Meio Ambiente (CONAMA). Resolução CONAMA n ${ }^{\circ} 307$, de 05 de julho de 2002. Estabelece diretrizes, critérios e procedimentos para a gestão dos resíduos da construção civil. Diário Oficial da União, Brasília - DF, n. 136, 17 jul. 2002, p.95-96. Disponível em: <http://www.mma.gov.br/port/conama/legiabre.cfm?codlegi=307>.Acessado em: 3 março de 2014.

[3] CÓRDOBA, R. E. Estudo do sistema de gerenciamento integrado de resíduos de construção e demolição do município de São Carlos - SP, Dissertação de M. Sc.,Escola de Engenharia de São Carlos, Universidade de São Paulo, USP, São Carlos, SP, 2010.

[4] SCREMIN, L.B. Desenvolvimento de um sistema de apoio ao gerenciamento de resíduos de construção e demolição para municípios de pequeno porte, Dissertação de M. Sc., Universidade Federal de Santa Catarina, UFSC, Florianópolis, SC, 2007.

[5] PINTO, T. P. Metodologia para a gestão diferenciada de resíduos sólidos da construção urbana, Tese de D. Sc., Escola Politécnica, Universidade de São Paulo, USP, São Paulo,SP,1999.

[6] GLOBO CIÊNCIA,http://redeglobo.globo.com/globociencia/noticia/2013/07/construcao-civil-consomeate-75-da-materia-prima-do-planeta.html. Acessado em: 25 de janeiro de 2015.

[7] CASSA, J. C., CARNEIRO, A. P., BRUM, I. A. S. Reciclagem de entulho para produção de materiais de construção: projeto entulho bom,1ed, EDUFBA, Salvador, BA, 2001.

[8] MARQUES NETO, J. C., SCHALCH, V. “Gestão dos resíduos de construção e demolição: estudo da situação no município de São Carlos-SP”, Engenharia Civil, v. 36, p. 41- 50, 2010.

[9] ASSOCIAÇÃO BRASILEIRA PARA RECICLAGEM DE RESÍDUOS DA CONSTRUÇÃO CIVIL E DEMOLIÇÃO - ABRECON. http://www.abrecon.org.br/. Acessado em 11 jan. 2017

[10] ASSOCIAÇÃO BRASILEIRA DE NORMAS TÉCNICAS,NBR 15116: Agregados reciclados de resíduos sólidos da construção civil: utilização em pavimentação e preparo de concreto sem função estrutural: requisitos, Rio de Janeiro, ABNT, 2004.

[11] SCATAMBURLO, L. F. A. A gestão dos resíduos da construção civil e o aproveitamento dos resíduos classe A e na produção de argamassa para revestimento, Monografia, Escola Politécnica, Universidade São Paulo, USP, São Paulo, SP, 2014.

[12] ARAÚJO, N. N. Desempenho de argamassas de revestimentos produzidas com agregados reciclados oriundos do resíduo de construção e demolição da Grande Natal-RN. Dissertação de M. Sc., Universidade Federal do Rio Grande do Norte, UFRN, Rio Grande do Norte, RN, 2014.

[13] MIRANDA, L. F. R., SELMO, S.M. S. "CDW recycled aggregate renderings: Part I - Analysis of the effect of materials finer than $75 \mu \mathrm{m}$ on mortar properties", Construction and Building Materials, v. 20, p. 615-624, 2006.

[14] RUDNITSKI, J. C., BAVASTRI, E. Y. N., MOHAMAD, G. "Avaliação do desempenho de argamassas de revestimento com adição de resíduos de construção e demolição - RCD”, In: Proceedings $55^{\circ}$ Congresso Brasileiro do Concreto. 15 p. Bento Gonçalves - RS, outubro 2013.

[15] MARTINEZ, P. S., GONZÁLEZ CORTINA, M., FERNÁNDEZ MARTINEZ, F., et al., "Comparative study of three types of fine recycled aggregates from construction and demolition waste (CDW), and their use in masonry mortar fabrication", Journal of Cleaner Production, v. 118, p. 162-169, 2016. 
[16] SILVA, N. G. Argamassa de revestimento de cimento, cal e areia britada de rocha calcária, Dissertação de M. Sc., Universidade Federal do Paraná, UFPR, Curitiba, PR, 2006.

[17] LEDESMA, E. F., JIMENEZ, J. R., AYUSO, J., et al., Maximum feasible use of recycled sand from construction and demolition waste for eco-mortar production e Part I: ceramic masonry waste", Journal of Cleaner Production, v. 87, pp. 692-706, 2015.

[18] LEDESMA, E. F., JIMENEZ, J. R., FERNANDEZ, J. M., et al., "Properties of masonry mortars manufactured with fine recycled concrete aggregates", Construction and Building Materials, v. 71, pp. 289-298, 2014.

[19] SAMIEI, R. R., DANIOTTI, B., PELOSATO,R.,et al. "Properties of cement-lime mortars vs. cement mortars containing recycled concrete aggregates", Construction and Building Materials, v. 84, pp. 84-94, 2015.

[20] SANTOS, M. L. L. O. Aproveitamento de resíduos minerais na formulação de argamassas para construção civil, Tese de D. Sc., Universidade Federal do Rio Grande do Norte, UFRN, Natal, RN, 2008.

[21] BREITENBACH, S. B. Desenvolvimento de argamassa para restauração utilizando resíduo do polimento do porcelanato, Tese de D. Sc., Universidade Federal do Rio Grande do Norte, UFRN, Natal, RN, 2013.

[22] ASSOCIAÇÃO BRASILEIRA DE NORMAS TÉCNICAS.NBR 13281:Argamassa para assentamento e revestimento de paredes e tetos: requisitos. Rio de Janeiro, ABNT, 2005a.

[23] MILITO, J.A., Técnicas de construção civil. Apostila. http://demilito.com.br/apostila.html.Acessado em janeiro de 2015.

[24] MIRANDA, L. F. R. Estudos de fatores que influenciam na fissuração de argamassas de revestimento com entulho reciclado, Dissertação de M. Sc. Escola Politécnica, Universidade de São Paulo, USP, São Paulo, 2000 .

[25] ASSOCIAÇÃO BRASILEIRA DE NORMAS TÉCNICAS,NBR 13276: argamassa para assentamento e revestimento de paredes e tetos: preparo da mistura e determinação do índice de consistência, Rio de Janeiro, 2005.

[26] ASSOCIAÇÃO BRASILEIRA DE NORMAS TÉCNICAS. NBR 13278: Argamassa para assentamento e revestimento de paredes e tetos: determinação da densidade de massa e do teor de ar incorporado. Rio de Janeiro, ABNT, 2005.

[27] ASSOCIAÇÃO BRASILEIRA DE NORMAS TÉCNICAS. NBR 13277:Argamassa para assentamento e revestimento de paredes e tetos: determinação da retenção de água, Rio de Janeiro, ABNT, 2005.

[28] ASSOCIAÇÃO BRASILEIRA DE NORMAS TÉCNICAS. NBR 13279:Argamassa para assentamento e revestimento de paredes e tetos: determinação da resistência à tração na flexão e à compressão, Rio de Janeiro, ABNT, 2005.

[29] ASSOCIAÇÃO BRASILEIRA DE NORMAS TÉCNICAS.NBR 15259: Argamassa para assentamento e revestimento de paredes e tetos: determinação da absorção de água por capilaridade e do coeficiente de capilaridade, Rio de Janeiro, ABNT, 2005.

[30] ASSOCIAÇÃO BRASILEIRA DE NORMAS TÉCNICAS. NBR 13280:Argamassa para assentamento e revestimento de paredes e tetos: determinação da densidade de massa aparente no estado endurecido, Rio de Janeiro, ABNT, 2005.

[31] ASSOCIAÇÃO BRASILEIRA DE NORMAS TÉCNICAS. NBR NM 7211:Agregado para concreto: especificação, Rio de Janeiro, ABNT, 2009.

[32] ASSOCIAÇÃO BRASILEIRA DE NORMAS TÉCNICAS. NBR 13749: Revestimento de paredes e tetos de argamassas inorgânicas: especificação, Rio de Janeiro, ABNT, 2013.

[33] CORREA, S. M. B. B. Probabilidade e estatística, 2.ed., Belo Horizonte, PUC Minas Virtual, 2003. 